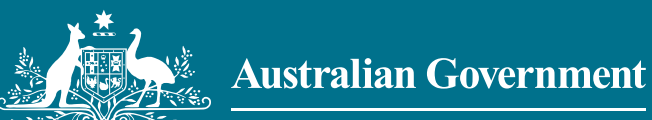

Geoscience Australia
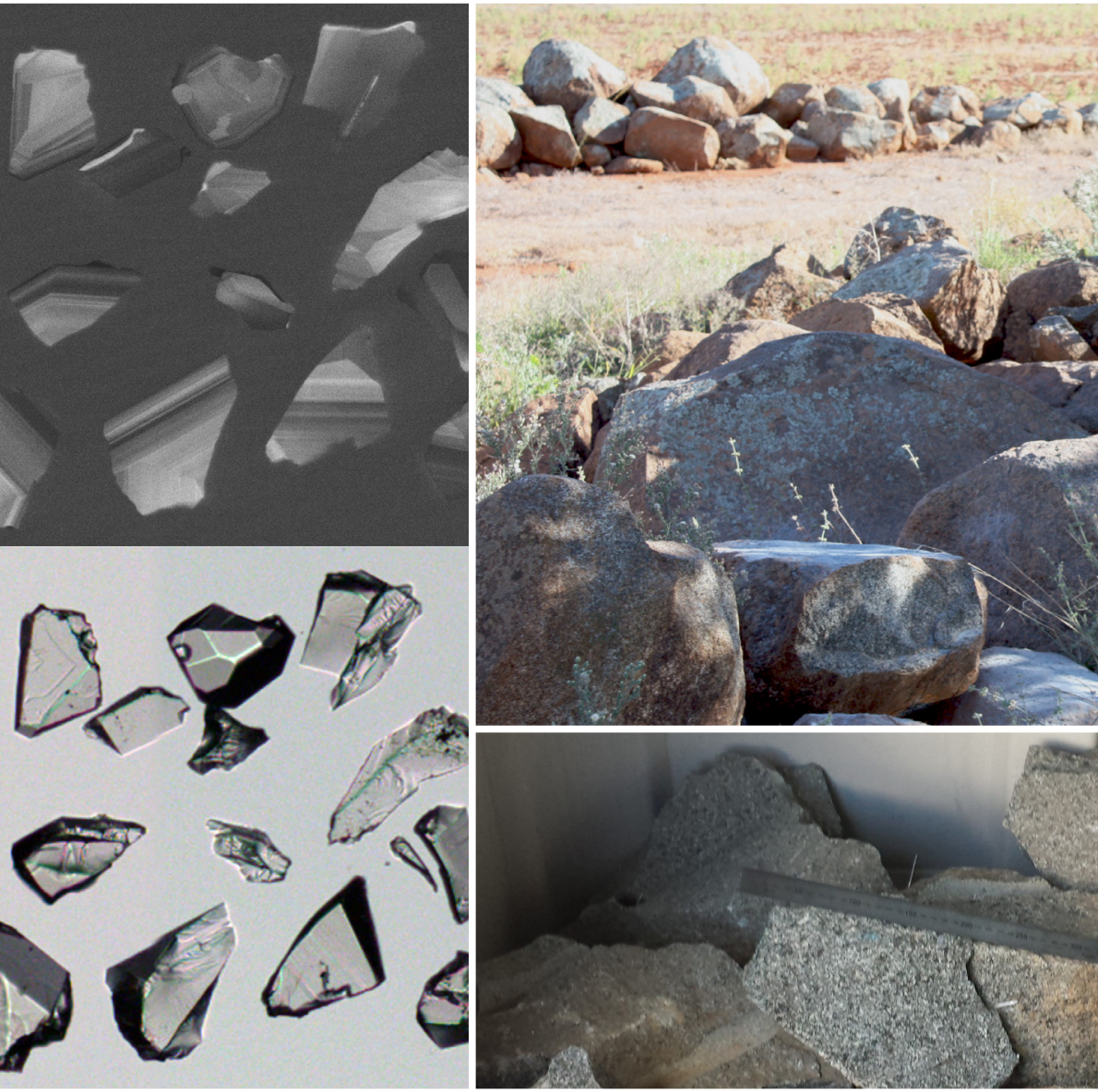

Record 2019/04 | eCat 127430

\title{
Oxygen isotopic heterogeneity in the Temora-2 reference zircon
}

A.K. Schmitt, C.W. Magee Jr., I.S. Williams, P. Holden, T.R. Ireland, D.L. DiBugnara and S. Bodorkos 



\section{Oxygen isotopic heterogeneity in the Temora-2 reference zircon}

RECORD 2019/04

Axel K. Schmitt ${ }^{1}$, Charles W. Magee Jr. ${ }^{2}$, Ian S. Williams ${ }^{3}$, Peter Holden ${ }^{3}$, Trevor R. Ireland ${ }^{3}$, David L. DiBugnara $^{2}$, Simon Bodorkos ${ }^{2}$
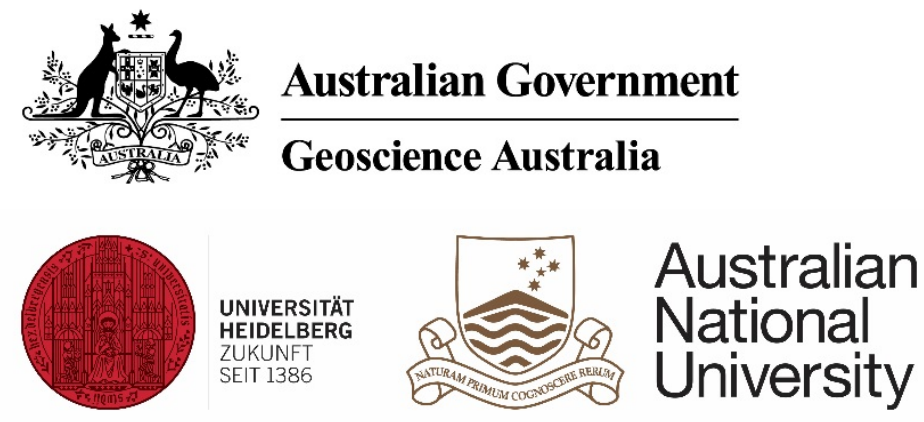

1. Institute for Earth Sciences, Heidelberg University, 69120 Heidelberg, Germany

2. Geoscience Australia, Symonston ACT 2609, Australia

3. Research School of Earth Sciences, Australian National University, Acton ACT 2601, Australia 


\section{Department of Industry, Innovation and Science}

Minister for Resources and Northern Australia: Senator the Hon. Matthew Canavan

Secretary: Dr Heather Smith PSM

\section{Geoscience Australia}

Chief Executive Officer: Dr James Johnson

This paper is published with the permission of the CEO, Geoscience Australia

Geoscience Australia acknowledges the traditional custodians of the country where this work was undertaken. We also acknowledge the support provided by individuals and communities to access the country, especially in remote and rural Australia.

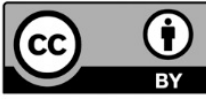

(c) Commonwealth of Australia (Geoscience Australia) 2019

With the exception of the Commonwealth Coat of Arms and where otherwise noted, this product is provided under a Creative Commons Attribution 4.0 International Licence.

(http://creativecommons.org/licenses/by/4.0/legalcode)

Geoscience Australia has tried to make the information in this product as accurate as possible. However, it does not guarantee that the information is totally accurate or complete. Therefore, you should not solely rely on this information when making a commercial decision.

Geoscience Australia is committed to providing web accessible content wherever possible. If you are having difficulties with accessing this document please email clientservices@ga.gov.au.

ISSN 2201-702X (PDF)

ISBN 978-1-925848-35-9 (PDF)

eCat 127430

Bibliographic reference: Schmitt, A. K., Magee, C. W. J., Williams, I. S., Holden, P., Ireland, T. R., DiBugnara, D. L., Bodorkos, S. 2019. Oxygen isotopic heterogeneity in the Temora-2 reference zircon. Record 2019/04. Geoscience Australia, Canberra. http://dx.doi.org/10.11636/Record.2019.004 


\section{Contents}

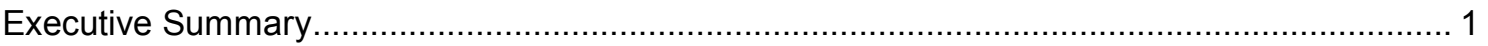

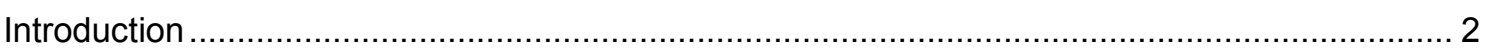

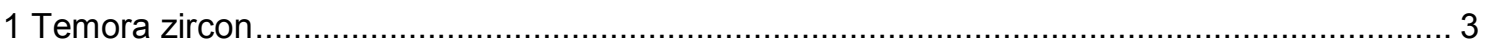

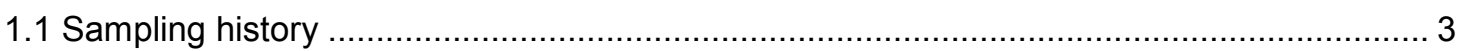

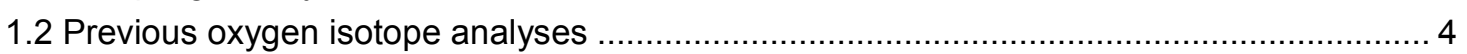

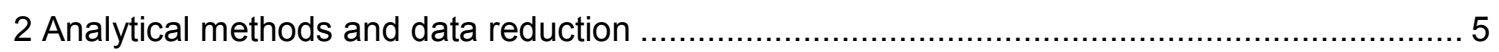

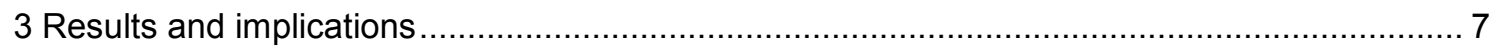

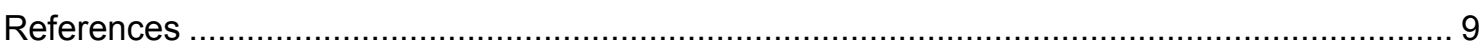

Appendix A Oxygen-isotope analytical data: CAMECA ims 1280-HR (HIP) ............................. 10

Appendix B Oxygen-isotope analytical data: SHRIMP SI (ANU) .......................................... 17 



\section{Executive Summary}

For the past decade and a half, Geoscience Australia has distributed zircon from a portion of the Middledale Gabbroic Diorite under the label "Temora-2". This reference zircon was originally developed as a reference material for use in ion microprobe $\mathrm{U}-\mathrm{Th}-\mathrm{Pb}$ geochronological analyses. As ion probe capability has increased to allow the measurements of other isotopic systems at geologically useful precision and accuracy, the Temora- 2 zircon has remained a convenient reference material to use for those systems. However, the suitability of this material for non-geochronological applications must be continuously reassessed.

This study demonstrates that some (but not all) aliquots of the Temora-2 zircon, distributed by Geoscience Australia to analytical laboratories worldwide, have $\delta^{18} \mathrm{O}$ values up to $1 \%$ lower than the reference laser fluorination $\delta^{18} \mathrm{O}$ value quoted in Black et al. (2004). Although the long and complex collection history of this material makes it difficult to pinpoint the cause of this discrepancy, we suspect it relates to material from two or more boulders from the Temora- 2 site, with different $\delta^{18} \mathrm{O}$ values, being sampled and mixed together in the field prior to storage at Geoscience Australia. Therefore, oxygen isotope measurements on SIMS mounts where Temora is the only reference zircon may be biased towards heavier values by up to $1 \%$, unless there are additional constrains on the actual $\delta^{18} \mathrm{O}$ value of the specific aliquot of Temora-2 zircons placed on that particular ion probe mount. We recommend that future oxygen isotope work should use a reference zircon other than Temora-2, until Geoscience Australia can replace the current stock of heterogeneous Temora-2 material with zircon which has a uniform $\delta^{18} \mathrm{O}$ value. 


\section{Introduction}

Secondary ionisation mass spectrometry (SIMS) analysis of the oxygen isotopic composition of many geomaterials has tremendous advantages compared to conventional stable isotope methods, in terms of speed and spatial resolution. However, accurate SIMS analysis requires reference materials which are (1) matrix-matched with the samples of interest, (2) well-characterised in terms of their chemical and isotopic compositions, and (3) sufficiently abundant that they are viable for long-term use within individual laboratories, as well as for inter-laboratory exchange to ensure data comparability.

Any uncertainty in the composition of the reference material must be propagated into the final uncertainty in the analyses of the unknown, as any inaccuracy in determining the composition of the reference material will produce inaccurate results. Thus the geoanalytical community is constantly looking for well characterised, abundant reference materials. For the mineral zircon, these materials are generally natural crystals, due to the difficulty in synthesising large, homogeneous crystals with compositions relevant to geochemistry and cosmochemistry.

Most reference zircons come chiefly from two sources: (1) megacrystic, gem-quality homogeneous crystals, which can be broken up, and have portions analysed conventionally with enough leftover material to distribute for in-situ analysis, and (2) multi-grain standards, extracted from igneous rocks which contain a single generation of cogenetic zircon. These multi-grain "isotopic standards" are generally not chemically homogeneous in all systems, but can be homogeneous in the isotopic system of interest (e.g. ${ }^{238} \mathrm{U} / 206 \mathrm{~Pb},{ }^{18} \mathrm{O} /{ }^{16} \mathrm{O}$ ), while demonstrating trace and minor element variation within and between grains that is within the same range as the unknown zircons to which they are being compared. As early, single megacryst reference zircons were falling out of favour in the last years of the twentieth century (Williams, 1998), attention turned to procuring higher quality multi-grain isotopic standards.

One such reference material is Temora zircon, from near the eponymous town in New South Wales, Australia. Temora zircon is sourced from the Middledale Gabbroic Diorite, a $\sim 3 \mathrm{~km}^{2}$ plutonic stock within the Paleozoic Lachlan Orogen. Originally introduced as a reference material for $\mathrm{U}-\mathrm{Pb}$ geochronology (Black et al., 2003), Temora zircon has since become a widely distributed microanalytical reference material for isotopic (e.g. oxygen, hafnium) and trace element (e.g. titanium) studies. The advantages of Temora zircon over individual, gem-quality zircon crystals sourced from museum collections or mineral dealers include: (1) its homogeneity in ${ }^{206} \mathrm{~Pb} / 238 \mathrm{U}$, which was superior to that of megacrystic reference zircons in use in the 1990s (Williams, 1998), (2) its natural variation in $\mathrm{U}, \mathrm{Th}$, and rare-earth elements, which is typical of zircon from igneous rocks, and (3) its theoretical ability to be easily replenished through re-sampling of its host rock in the field. However, over the last 20 years, the host rock for Temora zircon has been sampled on numerous occasions, and from multiple (albeit closely-spaced) sites, resulting in different batches of reference zircon. This raises the possibility of systematic differences in isotopic composition between batches.

Here, we report results from an inter-comparison of $\delta^{18} \mathrm{O}$ values between different batches of Temora-1 (Black et al., 2003) and Temora-2 (Black et al., 2004) zircon. The experiment involved the CAMECA ims 1280-HR ion microprobe at Heidelberg University (HIP), and SHRIMP SI at the Australian National University (ANU), in order to mitigate the potential effect of instrumental bias on the results. 


\section{Temora zircon}

\subsection{Sampling history}

The Middledale Gabbroic Diorite (MGD) was first sampled in 1998 by the Australian Geological Survey Organisation (AGSO; now Geoscience Australia) and the Geological Survey of New South Wales, as part of a regional mapping program. SHRIMP U-Pb analysis of the zircon extracted from this rock yielded ${ }^{206} \mathrm{~Pb} / 238 \mathrm{U}$ values that were considerably more uniform than those obtained from the concurrently analysed reference zircon (Black et al., 2003), indicating that the MGD zircon could be a useful reference material. At the time of initial sampling in 1998, this rock was assigned the Geoscience Australia sample identifier (SampleID) 98844520, and sample number (SampleNo) 1554096.

In 2000, a joint Geoscience Australia (GA)-Australian National University (ANU) team sampled three outcrops within the MGD, with the aim of developing a zircon reference material. The zircon extracted from these outcrops was named "Temora", after the nearest town (Black et al., 2003), and the extracts were designated Temora-1, Temora-2, and Temora-1.5.

1. The original 1998 sample site, which consists of a medium-grained, relatively zircon-poor $(\sim 10$ $\mathrm{mg} / \mathrm{kg}$ ) rock near the margin of the MGD, was defined as Temora-1. Resampling of the host rock (in 2000, and subsequent years) reused the original SampleID (98844520). Temora-1 zircon yielded an isotope dilution-thermal ionisation mass spectrometry (IDTIMS) ${ }^{206} \mathrm{~Pb} / 238 \mathrm{U}$ reference age of $416.75 \pm 0.24 \mathrm{Ma}$ (95\% confidence; Black et al., 2003).

2. A coarser-grained phase of the MGD, located a few hundred metres from the Temora- 1 site and featuring distinctive hornblende porphyroblasts, was initially sampled in 2000 (SampleID 2000844522; SampleNo 1555688). This site was defined as Temora-2. Subsequent resampling of the host rock reused the original SampleID. Temora-2 host rock proved considerably richer in zircon $(\sim 100 \mathrm{mg} / \mathrm{kg})$. That zircon yielded an IDTIMS ${ }^{206} \mathrm{~Pb} / 238 \mathrm{U}$ reference age of $416.78 \pm 0.33 \mathrm{Ma}$ (95\% confidence; Black et al., 2004), indistinguishable from the age of Temora-1.

3. A third outcrop (SampleID 2000844521; SampleNo 1597451), similar to SampleID 2000844522, was informally named "Temora-1.5" because it is located between the Temora-1 and Temora-2 sites (although Allen and Campbell (2012) dubbed it "Temora 3"). Zircon from this site was not independently characterised isotopically.

During the early 2000s, the Temora-1 and Temora-2 sites were resampled. This process included disaggregation of the "remainder of the big boulder of Temora-1 type", and extensive additional sampling of the Temora-2 site, "with a tonne or so of rock being taken." (L. P. Black, personal communication). At each site, this re-collected material comprised disaggregated boulders which were broken up (in the field) into liftable (5-25 kg) fragments, and packed into forklift-movable bins, now stored on-site at GA. All re-collected host rock was documented under the original SampleID (98844520 for Temora-1; 2000844522 for Temora-2); however, the aggregated zircon concentrates stored in GA's Mineral Separation Laboratory for routine use on SHRIMP mounts as reference zircons Temora-1 and Temora-2 were assigned new SampleNos (2129530 and 2129531, respectively).

By 2006, the Temora-1 and Temora-2 material, collected by GA in 2000 and documented by Black et al. (2003; 2004), had been exhausted. In order to maximise zircon yield and unify the reference material being distributed internationally, GA restricted the usage of Temora-1 and Temora-1.5, targeting instead the coarser-grained, zircon-rich host of Temora-2. 
Sample processing targeted the rock re-collected under SampleID 20008444522 in the early 2000s: on three separate occasions (2006, 2011, and 2013), a 200-300 kg aliquot was crushed and processed in order to replenish the global supply of Temora-2 zircon. The zircons extracted from these three bulk-crushes are the source of all Temora- 2 zircon aliquots used by GA, and distributed internationally as "Temora-2". In this study, the vials containing zircons derived from the 2006 bulk crush are labelled "Temora-II", while those from the 2011 and 2013 crushes are both labelled "Temora-2". As with the distributed zircon concentrates, all uncrushed Temora-2 rock distributed by GA since the mid-2000s is derived from the same batch of material i.e. rock re-collected under SampleID 20008444522 in the early 2000s.

In February 2010, a further 26 tonnes of rock were re-collected from the Temora-2 site as very large, intact boulders and tors, using a front-end loader and heavy trucks. The aim was to ensure a longterm supply of Temora-2 rock, should site access issues arise in future. This material is stored on-site at GA; however, none of it has yet been processed for zircon, or distributed as unprocessed rock.

\subsection{Previous oxygen isotope analyses}

Black et al. (2004) reported laser fluorination (LF) oxygen-isotope data for both Temora-1 and Temora-2, on zircon derived from rock collected during the joint GA-ANU sampling exercise in 2000. These analyses showed minor but significant differences in $\delta^{18} \mathrm{O}_{\text {SMOW }}(7.93 \pm 0.03 \%$ and $8.20 \pm 0.03 \%$ respectively).

SIMS oxygen isotope data for Temora zircon have been reported in two other studies: the informally named "Temora 3" (Allen and Campbell, 2012), and a series of samples across the MGD, named Sites A, B, J, and $\mathrm{N}$ (lles et al., 2015). Collectively, these results indicate a range of $\delta^{18} \mathrm{O}_{\text {SMOW }}$ values between $7.5 \%$ and $8.4 \%$. Some of these overlap with the LF values determined by Black et al. (2004), but most are significantly lower.

In this experiment, zircon from the 2006, 2011, and 2013 crushes, which have been distributed to the geochronological community and used internally at GA, were analysed using ion probes for $\delta^{18} \mathrm{O}$ to see if they are consistent with the published Black et al. (2004) values. 


\section{Analytical methods and data reduction}

An epoxy mount was prepared at Heidelberg University by mounting five aliquots of Temora zircon (each comprising 20-30 individual crystals) alongside multiple fragments of reference zircons AS3 and 91500. All but one of the Temora zircon aliquots were supplied to Heidelberg University by GA for the purpose of this experiment, as follows:

- Temora-1

- Temora-II 2006

- Temora-2 2011

- Temora-2 2011 HIP (supplied to Heidelberg University in 2016, prior to this experiment)

- Temora-2 2013

Care was taken to arrange grains within the inner $1 \mathrm{~cm}$ bulls-eye of a $2.54 \mathrm{~cm}$ diameter mount. Zircon crystals were embedded in Struers ${ }^{\mathrm{TM}}$ Caldofix ${ }^{\mathrm{TM}}$ epoxy and exposed by grinding with $\mathrm{SiC}$ paper (Type 4000, Federation of European Producers of Abrasives), followed by final polishing with $1 \mu \mathrm{m}$ diamond embedded in polyethylene sheets to reduce surface topography. After cleaning with deionised water and methanol, the mount was coated with $\sim 50 \mathrm{~nm}$ Au using a Quorum Technologies ${ }^{\mathrm{TM}}$ Q150T sputter coater.

CAMECA ims $1280-\mathrm{HR}$ analysis was carried out at HIP by sputtering with a $\sim 2 \mathrm{nA} \mathrm{Cs}{ }^{+}$primary ion beam focussed into a $\sim 5 \mu \mathrm{m}$ spot rastered over $10 \times 10 \mu \mathrm{m}$ with a normal-incidence electron gun held at equipotential with the sample for charge compensation. Negative secondary ions were detected in multi-collection $\left({ }^{16} \mathrm{O},{ }^{16} \mathrm{OH},{ }^{18} \mathrm{O}\right)$ using Faraday cups and transmission settings (open contrast and field apertures, $60 \mu \mathrm{m}$ field of view, energy slit width $40 \mathrm{eV}$ ) to generate flat-topped peaks at a mass resolving power (full peak width at $10 \%$ of maximum intensity) of $\sim 2000$ at $\sim 2.3 \mathrm{GHz}$ for ${ }^{16} \mathrm{O}$. Contrast and field aperture deflectors were automatically centered prior to each analysis. Faraday backgrounds were recorded during a 20 -second pre-sputtering, and averaged over the course of the automated session ( 8.5 hours). Instrumental mass fractionation (IMF) corrections used bracketing and interspersed analyses of AS3 and 91500 reference zircons. No IMF drift was detected, and the standard deviation of IMF values was $0.17 \%$ over the course of the session.

The mount was subsequently shipped to ANU, repolished, cleaned with petroleum spirit, warm Thermo Scientific ${ }^{\mathrm{TM}}$ RBS35 ${ }^{\mathrm{TM}}$ detergent solution and deionised water, and recoated with $\sim 11 \mathrm{~nm}$ Al prior to analysis on SHRIMP SI. A $15 \mathrm{kV} \mathrm{Cs}^{+}$beam, focused in Köhler mode to a $30 \times 40 \mu \mathrm{m}$ spot, was used with an oblique medium energy $(\sim 1 \mathrm{kV})$ electron gun for charge compensation at a secondary ion transmission of $\sim 1.8 \mathrm{GHz}$ for ${ }^{16} \mathrm{O}$. Measured ratios were corrected for electron-induced secondary ion emission $\left(\sim 1 \mathrm{MHz}{ }^{16} \mathrm{O}^{-}\right)$, and constant IMF was observed for the duration of the automated run (0.09\%o drift over 18 hours). Backgrounds were measured during 2 minutes of pre-sputtering.

For both datasets, we calculated means of background-corrected measured ratios for reference zircons 91500 (LF = $9.86 \%$; Wiedenbeck et al., 2004) and AS3 (LF = $5.34 \%$; Trail et al., 2007) to derive independent instrumental mass fractionation (IMF) correction factors, and we used the average of the two factors to perform IMF correction in the Temora unknowns. The reference zircons were analysed bracketing and interspersed with the unknowns throughout the session. For 91500, AS3, and each aliquot of Temora zircon, the uncertainty associated with each arithmetic mean was calculated accounting for the observed standard deviation of replicate analyses $(n=20$ for AS3 and each aliquot 
of Temora zircon, $n \geq 40$ for 91500 ), divided by the square-root of $n-1$. For each aliquot of Temora zircon, the errors on the population mean and the IMF correction were added in quadrature, and the radical multiplied by Student's $t$ for $n-1$ degrees of freedom (i.e. $\sim 2.09$ where $n=20$ ) to yield the $95 \%$ confidence interval.

Appendix A contains the full analytical dataset from HIP, comprising analyses of the reference zircons 91500 and AS3 (Appendix Table A.1), as well as analyses of the five Temora zircon aliquots (Appendix Table A.2). The corresponding analytical datasets from ANU are presented in Appendix B (Appendix Table B.1; Appendix Table B.2). Both Appendices are also supplied as a Microsoft Excel spreadsheet. 


\section{Results and implications}

The results from both laboratories closely agree, and display a range in $\delta^{18} \mathrm{O}_{\text {SMOW }}$ between 7.3 and $8.1 \%$ for different aliquots of Temora zircon (Table 3.1; Figure 3.1). It is important to note that because each lab handles IMF, standardisation, and uncertainty propagation differently, these data do not compare the analytical precision between the SHRIMP SI and CAMECA ims 1280-HR instruments. Rather, they show that the two different methodologies and instruments produce very similar results.

In both datasets, inter-grain variability within each aliquot of Temora zircon is similar to the external reproducibility of reference zircons 91500 and AS3, and the mean value for each batch proved highly repeatable across laboratories, despite the HIP and ANU experiments being separated by an episode of mount preparation that included removal of zircon material during regrinding and polishing. These observations indicate that individual batches of Temora zircon crystals are homogeneous within SIMS analytical uncertainty. Moreover, two vials from the same batch (Temora-2 2011 HIP and Temora-2 2011) yield indistinguishable results. All SIMS $\delta^{18} \mathrm{O}_{\text {SMOW }}$ values obtained from the various aliquots of Temora-2 2011 and Temora-2 2013 are significantly lower than the SIMS $\delta^{18} \mathrm{O}_{\text {SMOW }}$ values for Temora-II 2006 and Temora-1, and well below the reference LF $\delta^{18} \mathrm{O}_{\text {SMow }}$ values for both Temora-1 and Temora-2. SIMS $\delta^{18} \mathrm{O}_{\text {SMOW }}$ averages for the earliest Temora-2 separation (Temora-II 2006) are $\sim 0.2 \%$ lower than the Temora-2 LF value, and a similar offset is observed between SIMS and LF data for Temora-1 (Figure 3.1).

Table 3.1 Summary of Temora zircon oxygen isotope inter-comparison (HIP = Heidelberg University CAMECA ims 1280-HR; ANU = Australian National University SHRIMP SI).

\begin{tabular}{|c|c|c|c|c|c|c|c|c|}
\hline & $\begin{array}{r}\text { HIP weighted } \\
\text { mean } \delta^{18} 0_{\text {smow }} \\
(\% 0)^{1}\end{array}$ & $\begin{array}{r}\text { HIP } \\
\pm c 95 \% \\
(\% \circ)^{2}\end{array}$ & $\begin{array}{r}\text { HIP } \\
\pm 1 \text { s.d. } \\
(\% \circ)^{3}\end{array}$ & $\begin{array}{r}\text { HIP } \\
n^{4}\end{array}$ & $\begin{array}{r}\text { ANU weighted } \\
\text { mean } \delta^{18} O_{\text {SMOw }} \\
(\% 0)^{1}\end{array}$ & $\begin{array}{r}\text { ANU } \\
\pm \mathrm{c} 95 \% \\
(\% 0)^{2}\end{array}$ & $\begin{array}{r}\text { ANU } \\
\pm 1 \text { s.d. } \\
(\% o)^{3}\end{array}$ & $\begin{array}{r}\text { ANU } \\
n^{4}\end{array}$ \\
\hline 91500 & 9.86 & 0.05 & 0.10 & 44 & 9.95 & 0.13 & 0.21 & 22 \\
\hline AS3 & 5.37 & 0.10 & 0.20 & 20 & 5.25 & 0.13 & 0.23 & 20 \\
\hline Temora-1 & 7.57 & 0.09 & 0.17 & 20 & 7.58 & 0.14 & 0.23 & 20 \\
\hline $\begin{array}{l}\text { Temora-II } \\
2006\end{array}$ & 7.93 & 0.11 & 0.21 & 20 & 8.05 & 0.14 & 0.23 & 20 \\
\hline $\begin{array}{l}\text { Temora-2 } \\
2011\end{array}$ & 7.32 & 0.07 & 0.12 & 20 & 7.33 & 0.13 & 0.21 & 20 \\
\hline $\begin{array}{l}\text { Temora-2 } \\
2011 \text { HIP }\end{array}$ & 7.35 & 0.09 & 0.17 & 20 & 7.31 & 0.11 & 0.14 & 20 \\
\hline $\begin{array}{l}\text { Temora-2 } \\
2013\end{array}$ & 7.37 & 0.08 & 0.14 & 20 & 7.37 & 0.10 & 0.14 & 20 \\
\hline
\end{tabular}

1. Error-weighted mean of population; corrected for instrumental mass fractionation (IMF) using the average of the IMF factor determined from the concurrently-acquired 91500 (normalised to $\delta^{18} \mathrm{O}_{S M O W}=9.86 \%$ ) and $A S 3$ (normalised to $\delta^{18} \mathrm{O}_{\text {SMOW }}=$ $5.34 \%$ ) datasets.

2. 95\% confidence interval includes both the standard error of the mean and the standard error of the mean IMF correction factor.

3. s.d. = standard deviation.

4. $n=$ number of analyses in the population. 


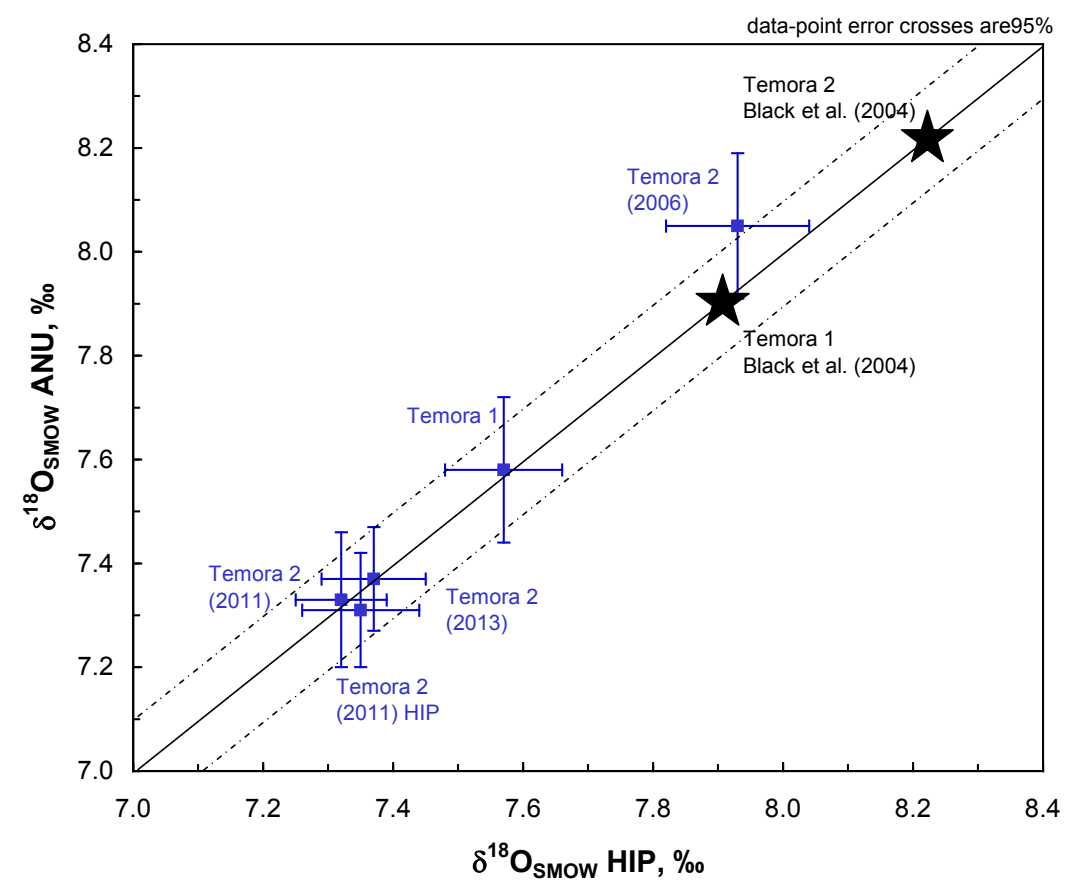

Figure 3.1 Oxygen isotopic compositions of Temora zircon (blue) determined by SIMS (HIP = Heidelberg University CAMECA ims 1280-HR; ANU = Australian National University SHRIMP SI). Laser fluorination (LF) averages from Black et al. (2004) are shown for comparison (black stars; analytical errors are within symbol size).

lles et al. (2015) documented a negative correlation between $\delta^{18} \mathrm{O}$ and $\varepsilon_{\mathrm{Hf}}$ in Temora zircon, and suggested that zircon from the MGD is isotopically heterogeneous, probably as a consequence of progressive crustal contamination during magmatic evolution of the pluton. The results of our intercomparison support this contention, and we urge caution in using Temora zircon as a reference for oxygen isotope analysis by SIMS, unless the material is characterised by laser fluorination data for zircon aliquots from identical batches used for microanalytical zircon reference extraction. Mixing spatially and texturally different blocks and boulders of Temora host rocks should be avoided, as this potentially introduces heterogeneity within the zircon population which appears to be absent at the scale the original samples were processed. Temora zircon is known to be homogeneous in its U-Pb age, consistent with comparatively rapid magmatic evolution of the small MGD stock, but the oxygen isotopic heterogeneity documented here could reasonably be expected to extend to $\mathrm{Hf}$ isotopes.

Geoscience Australia plans to examine and test one of the large intact boulders collected in 2010, in order to determine whether homogeneity in zircon $\delta^{18} \mathrm{O}$ can be established at that scale. 


\section{References}

Allen, C. M. and Campbell, I. H., 2012. Identification and elimination of a matrix-induced systematic error in LA-ICP-MS ${ }^{206} \mathrm{~Pb} / 238 \mathrm{U}$ dating of zircon. Chemical Geology, 332-333, 157-165. https://doi.org/10.1016/j.chemgeo.2012.09.038

Black, L. P., Kamo, S. L., Allen, C. M., Aleinikoff, J. N., Davis, D. W., Korsch, R. J. and Foudoulis, C., 2003. TEMORA 1: a new zircon standard for Phanerozoic U-Pb geochronology. Chemical Geology, 200(1-2), 155-170. https://doi.org/10.1016/S0009-2541(03)00165-7

Black, L. P., Kamo, S. L., Allen, C. M., Davis, D. W., Aleinikoff, J. N., Valley, J. W., Mundil, R., Campbell, I. H., Korsch, R. J., Williams, I. S. and Foudoulis, C., 2004. Improved ${ }^{206} \mathrm{~Pb} / 238 \mathrm{U}$ microprobe geochronology by the monitoring of a trace-element-related matrix effect; SHRIMP, IDTIMS, ELA-ICP-MS and oxygen isotope documentation for a series of zircon standards. Chemical Geology, 205(1-2), 115-140. https://doi.org/10.1016/j.chemgeo.2004.01.003

Iles, K. A., Hergt, J. M., Sircombe, K. N., Woodhead, J. D., Bodorkos, S. and Williams, I. S., 2015. Portrait of a reference material: Zircon production in the Middledale Gabbroic Diorite, Australia, and its implications for the TEMORA standard. Chemical Geology, 402, 140-152. https://doi.org/10.1016/j.chemgeo.2015.02.036

Trail, D., Mojzsis, S. J., Harrison, T. M., Schmitt, A. K., Watson, E. B. and Young, E. D., 2007. Constraints on Hadean zircon protoliths from oxygen isotopes, Ti thermometry, and rare earth elements. Geochemistry, Geophysics, Geosystems, 8(6). https://doi.org/10.1029/2006GC001449

Wiedenbeck, M., Hanchar, J. M., Peck, W. H., Sylvester, P., Valley, J., Whitehouse, M., Kronz, A., Morishita, Y., Nasdala, L., Fiebig, J. and Franchi, I., 2004. Further characterisation of the 91500 zircon crystal. Geostandards and Geoanalytical Research, 28(1), 9-39. https://doi.org/10.1111/j.1751-908X.2004.tb01041.x

Williams, I. S., 1998. U-Th-Pb geochronology by ion microprobe. In: McKibben, M. A., Shanks III, W. C., and Ridley, W. I. (eds.) Applications of Microanalytical Techniques to Understanding Mineralizing Processes. Reviews in Economic Geology 7, pp. 1-35. 


\section{Appendix A Oxygen-isotope analytical data: CAMECA ims 1280-HR (HIP)}

Appendix Table A.1 CAMECA ims 1280-HR (HIP) analyses of reference zircons 91500 and AS3. IMF correction factors were calculated from both datasets, and the average used to perform the IMF correction on analyses of the five Temora zircon aliquots (Temora-1, Temora-II 2006, Temora-2 2011, Temora-2 2011 HIP, and Temora-2 2013).

\begin{tabular}{|c|c|c|c|c|c|c|c|}
\hline Grain.spot & $\begin{array}{r}\text { Acquisition } \\
\text { order }\end{array}$ & $\begin{array}{l}{ }^{16} \mathrm{O} \text { count } \\
\text { rate }(\mathrm{GHz})\end{array}$ & ${ }^{18} \mathrm{O} /{ }^{16} \mathrm{O}^{1}$ & $\pm c 95 \%{ }^{2}$ & $\begin{array}{r}\delta^{18} \mathrm{O}_{\text {sMow }}{ }^{3} \\
(\% 0)\end{array}$ & $\begin{array}{l} \pm 1 \sigma \\
(\% 0)\end{array}$ & $\begin{array}{r} \pm c 95 \%{ }^{2} \\
(\% \circ)\end{array}$ \\
\hline \multicolumn{8}{|l|}{91500} \\
\hline 1.1 & 1 & 2.41 & 0.00202716 & 0.00000035 & 9.91 & 0.084 & 0.18 \\
\hline 2.1 & 2 & 2.41 & 0.00202719 & 0.00000030 & 9.92 & 0.072 & 0.15 \\
\hline 3.1 & 9 & 2.40 & 0.00202709 & 0.00000030 & 9.87 & 0.072 & 0.15 \\
\hline 4.1 & 10 & 2.41 & 0.00202741 & 0.00000047 & 9.86 & 0.110 & 0.23 \\
\hline 5.1 & 17 & 2.41 & 0.00202743 & 0.00000044 & 9.87 & 0.104 & 0.22 \\
\hline 6.1 & 18 & 2.40 & 0.00202759 & 0.00000041 & 9.96 & 0.097 & 0.20 \\
\hline 7.1 & 25 & 2.41 & 0.00202700 & 0.00000039 & 9.67 & 0.093 & 0.19 \\
\hline 8.1 & 26 & 2.39 & 0.00202724 & 0.00000033 & 9.93 & 0.078 & 0.16 \\
\hline 9.1 & 33 & 2.38 & 0.00202674 & 0.00000038 & 9.68 & 0.090 & 0.19 \\
\hline 10.1 & 34 & 2.38 & 0.00202707 & 0.00000049 & 9.95 & 0.116 & 0.24 \\
\hline 11.1 & 41 & 2.37 & 0.00202721 & 0.00000043 & 10.02 & 0.103 & 0.21 \\
\hline 12.1 & 42 & 2.35 & 0.00202710 & 0.00000044 & 9.82 & 0.104 & 0.22 \\
\hline 13.1 & 49 & 2.36 & 0.00202728 & 0.00000053 & 9.91 & 0.125 & 0.26 \\
\hline 14.1 & 50 & 2.34 & 0.00202665 & 0.00000031 & 9.73 & 0.073 & 0.15 \\
\hline 15.1 & 57 & 2.35 & 0.00202681 & 0.00000043 & 9.81 & 0.101 & 0.21 \\
\hline 16.1 & 58 & 2.34 & 0.00202687 & 0.00000042 & 9.77 & 0.098 & 0.20 \\
\hline 17.1 & 65 & 2.34 & 0.00202747 & 0.00000034 & 10.07 & 0.079 & 0.17 \\
\hline 18.1 & 66 & 2.35 & 0.00202704 & 0.00000048 & 9.82 & 0.113 & 0.24 \\
\hline 19.1 & 73 & 2.35 & 0.00202699 & 0.00000033 & 9.79 & 0.078 & 0.16 \\
\hline 20.1 & 74 & 2.36 & 0.00202699 & 0.00000039 & 9.76 & 0.091 & 0.19 \\
\hline 21.1 & 81 & 2.35 & 0.00202739 & 0.00000029 & 9.96 & 0.068 & 0.14 \\
\hline 22.1 & 82 & 2.34 & 0.00202738 & 0.00000036 & 9.98 & 0.085 & 0.18 \\
\hline 23.1 & 89 & 2.34 & 0.00202693 & 0.00000039 & 9.75 & 0.091 & 0.19 \\
\hline
\end{tabular}




\begin{tabular}{|c|c|c|c|c|c|c|c|}
\hline Grain.spot & $\begin{array}{r}\text { Acquisition } \\
\text { order }\end{array}$ & $\begin{array}{l}{ }^{16} \mathrm{O} \text { count } \\
\text { rate }(\mathrm{GHz})\end{array}$ & ${ }^{18} \mathrm{O}^{16} \mathrm{O}^{1}$ & $\pm c 95 \% \%^{2}$ & $\begin{array}{r}\delta^{18} \mathrm{O}_{\text {smow }}{ }^{3} \\
(\%)\end{array}$ & $\begin{array}{l} \pm 1 \sigma \\
(\%)\end{array}$ & $\begin{array}{r} \pm c 95 \% \%^{2} \\
(\%)\end{array}$ \\
\hline 24.1 & 90 & 2.34 & 0.00202687 & 0.00000041 & 9.89 & 0.096 & 0.20 \\
\hline 25.1 & 97 & 2.34 & 0.00202665 & 0.00000030 & 9.78 & 0.072 & 0.15 \\
\hline 26.1 & 98 & 2.34 & 0.00202681 & 0.00000041 & 9.86 & 0.097 & 0.20 \\
\hline 27.1 & 99 & 2.17 & 0.00202647 & 0.00000039 & 9.69 & 0.093 & 0.19 \\
\hline 28.1 & 100 & 2.13 & 0.00202672 & 0.00000039 & 9.81 & 0.093 & 0.19 \\
\hline 29.1 & 107 & 2.12 & 0.00202676 & 0.00000039 & 9.84 & 0.091 & 0.19 \\
\hline 30.1 & 108 & 2.12 & 0.00202661 & 0.00000041 & 9.69 & 0.096 & 0.20 \\
\hline 31.1 & 115 & 2.09 & 0.00202691 & 0.00000044 & 9.84 & 0.105 & 0.22 \\
\hline 32.1 & 116 & 2.12 & 0.00202718 & 0.00000038 & 9.91 & 0.091 & 0.19 \\
\hline 33.1 & 123 & 2.11 & 0.00202678 & 0.00000039 & 9.71 & 0.091 & 0.19 \\
\hline 34.1 & 124 & 2.10 & 0.00202766 & 0.00000056 & 10.10 & 0.131 & 0.27 \\
\hline 35.1 & 131 & 2.11 & 0.00202705 & 0.00000039 & 9.80 & 0.093 & 0.19 \\
\hline 36.1 & 132 & 2.10 & 0.00202714 & 0.00000040 & 9.82 & 0.095 & 0.20 \\
\hline 37.1 & 139 & 2.10 & 0.00202732 & 0.00000045 & 9.91 & 0.106 & 0.22 \\
\hline 38.1 & 140 & 2.09 & 0.00202739 & 0.00000027 & 9.87 & 0.065 & 0.13 \\
\hline 39.1 & 147 & 2.08 & 0.00202728 & 0.00000050 & 9.81 & 0.117 & 0.25 \\
\hline 40.1 & 148 & 2.09 & 0.00202750 & 0.00000038 & 9.94 & 0.090 & 0.19 \\
\hline 41.1 & 155 & 2.08 & 0.00202708 & 0.00000035 & 9.74 & 0.083 & 0.17 \\
\hline 42.1 & 156 & 2.08 & 0.00202748 & 0.00000043 & 9.98 & 0.101 & 0.21 \\
\hline 43.1 & 163 & 2.06 & 0.00202699 & 0.00000046 & 9.74 & 0.109 & 0.23 \\
\hline 44.1 & 164 & 2.06 & 0.00202741 & 0.00000033 & 9.94 & 0.079 & 0.16 \\
\hline \multicolumn{8}{|l|}{ AS3 } \\
\hline 1.1 & 3 & 2.39 & 0.00201830 & 0.00000042 & 5.49 & 0.100 & 0.21 \\
\hline 2.1 & 4 & 2.40 & 0.00201711 & 0.00000038 & 4.90 & 0.090 & 0.19 \\
\hline 3.1 & 11 & 2.39 & 0.00201811 & 0.00000033 & 5.23 & 0.078 & 0.16 \\
\hline 4.1 & 12 & 2.39 & 0.00201865 & 0.00000037 & 5.50 & 0.087 & 0.18 \\
\hline 5.1 & 19 & 2.38 & 0.00201818 & 0.00000034 & 5.28 & 0.082 & 0.17 \\
\hline 6.1 & 20 & 2.38 & 0.00201870 & 0.00000047 & 5.54 & 0.111 & 0.23 \\
\hline 7.1 & 27 & 2.38 & 0.00201800 & 0.00000045 & 5.33 & 0.106 & 0.22 \\
\hline 8.1 & 28 & 2.38 & 0.00201840 & 0.00000041 & 5.53 & 0.098 & 0.20 \\
\hline 9.1 & 35 & 2.37 & 0.00201802 & 0.00000033 & 5.44 & 0.078 & 0.16 \\
\hline
\end{tabular}




\begin{tabular}{|c|c|c|c|c|c|c|c|}
\hline Grain.spot & $\begin{array}{r}\text { Acquisition } \\
\text { order }\end{array}$ & $\begin{array}{c}{ }^{16} \mathrm{O} \text { count } \\
\text { rate }(\mathrm{GHz})\end{array}$ & ${ }^{18} \mathrm{O} /{ }^{16} \mathrm{O}^{1}$ & $\pm c 95 \%{ }^{2}$ & $\begin{array}{r}\delta^{18} \mathrm{O}_{\text {sMow }}{ }^{3} \\
(\% 0)\end{array}$ & $\begin{array}{l} \pm 1 \sigma \\
(\% \circ)\end{array}$ & $\begin{array}{r} \pm c 95 \% 2 \\
(\% 0)\end{array}$ \\
\hline 10.1 & 36 & 2.38 & 0.00201704 & 0.00000038 & 4.95 & 0.091 & 0.19 \\
\hline 11.1 & 43 & 2.37 & 0.00201857 & 0.00000035 & 5.57 & 0.082 & 0.17 \\
\hline 12.1 & 44 & 2.35 & 0.00201810 & 0.00000040 & 5.34 & 0.096 & 0.20 \\
\hline 13.1 & 101 & 2.13 & 0.00201824 & 0.00000028 & 5.59 & 0.066 & 0.14 \\
\hline 14.1 & 102 & 2.13 & 0.00201790 & 0.00000049 & 5.42 & 0.117 & 0.24 \\
\hline 15.1 & 109 & 2.12 & 0.00201758 & 0.00000039 & 5.19 & 0.093 & 0.19 \\
\hline 16.1 & 110 & 2.13 & 0.00201852 & 0.00000046 & 5.66 & 0.109 & 0.23 \\
\hline 17.1 & 117 & 2.11 & 0.00201767 & 0.00000050 & 5.17 & 0.119 & 0.25 \\
\hline 18.1 & 118 & 2.11 & 0.00201816 & 0.00000034 & 5.41 & 0.080 & 0.17 \\
\hline 19.1 & 125 & 2.09 & 0.00201813 & 0.00000038 & 5.36 & 0.091 & 0.19 \\
\hline 20.1 & 126 & 2.10 & 0.00201810 & 0.00000055 & 5.34 & 0.131 & 0.27 \\
\hline
\end{tabular}

1. HIP: Raw intensity ratios corrected for background and detector gain.

2. $95 \%$ confidence interval includes the $t$-distribution factor for replicate cycles.

3. Corrected for instrumental mass fractionation (IMF) using the average of the IMF factors determined from the HIP 91500 (normalised to $\delta^{18} O_{S M O W}=9.86 \%$ ) and HIP AS3 (normalised to $\delta^{18} O_{S M O W}=5.34 \%$ ) datasets. 
Appendix Table A.2 CAMECA ims 1280-HR (HIP) analyses of five Temora zircon aliquots (Temora-1, Temora-II 2006, Temora-2 2011, Temora-2 2011 HIP, and Temora-2 2013) as unknowns, IMF-corrected using the average of the IMF factors determined from the two reference zircons 91500 and AS3.

\begin{tabular}{|c|c|c|c|c|c|c|c|}
\hline Grain.spot & $\begin{array}{r}\text { Acquisition } \\
\text { order }\end{array}$ & $\begin{array}{l}{ }^{16} \mathrm{O} \text { count } \\
\text { rate }(\mathrm{GHz})\end{array}$ & ${ }^{18} \mathrm{O} /{ }^{16} \mathrm{O}^{1}$ & $\pm c 95 \%{ }^{2}$ & $\begin{array}{r}\delta^{18} O_{\text {sMow }}{ }^{3} \\
(\% 0)\end{array}$ & $\begin{array}{l} \pm 1 \sigma \\
(\% 0)\end{array}$ & $\begin{array}{r} \pm c 95 \%{ }^{2} \\
(\% 0)\end{array}$ \\
\hline \multicolumn{8}{|l|}{ Temora-1 } \\
\hline 1.1 & 55 & 2.31 & 0.00202258 & 0.00000043 & 7.71 & 0.103 & 0.21 \\
\hline 2.1 & 56 & 2.32 & 0.00202264 & 0.00000041 & 7.74 & 0.097 & 0.20 \\
\hline 3.1 & 63 & 2.32 & 0.00202243 & 0.00000036 & 7.56 & 0.086 & 0.18 \\
\hline 4.1 & 64 & 2.31 & 0.00202225 & 0.00000043 & 7.47 & 0.102 & 0.21 \\
\hline 5.1 & 71 & 2.32 & 0.00202266 & 0.00000034 & 7.64 & 0.081 & 0.17 \\
\hline 6.1 & 72 & 2.32 & 0.00202185 & 0.00000027 & 7.24 & 0.063 & 0.13 \\
\hline 7.1 & 79 & 2.32 & 0.00202292 & 0.00000042 & 7.73 & 0.099 & 0.21 \\
\hline 8.1 & 80 & 2.32 & 0.00202279 & 0.00000044 & 7.67 & 0.104 & 0.22 \\
\hline 9.1 & 87 & 2.33 & 0.00202256 & 0.00000043 & 7.58 & 0.103 & 0.21 \\
\hline 10.1 & 88 & 2.32 & 0.00202222 & 0.00000056 & 7.41 & 0.132 & 0.28 \\
\hline 11.1 & 95 & 2.32 & 0.00202272 & 0.00000043 & 7.82 & 0.101 & 0.21 \\
\hline 12.1 & 96 & 2.32 & 0.00202279 & 0.00000041 & 7.85 & 0.096 & 0.20 \\
\hline 13.1 & 137 & 2.07 & 0.00202289 & 0.00000055 & 7.70 & 0.129 & 0.27 \\
\hline 14.1 & 138 & 2.06 & 0.00202267 & 0.00000040 & 7.59 & 0.094 & 0.20 \\
\hline 15.1 & 145 & 2.06 & 0.00202295 & 0.00000043 & 7.66 & 0.101 & 0.21 \\
\hline 16.1 & 146 & 2.07 & 0.00202236 & 0.00000053 & 7.36 & 0.126 & 0.26 \\
\hline 17.1 & 153 & 2.06 & 0.00202292 & 0.00000044 & 7.66 & 0.103 & 0.22 \\
\hline 18.1 & 154 & 2.05 & 0.00202239 & 0.00000044 & 7.40 & 0.104 & 0.22 \\
\hline 19.1 & 161 & 2.05 & 0.00202300 & 0.00000062 & 7.75 & 0.147 & 0.31 \\
\hline 20.1 & 162 & 2.05 & 0.00202225 & 0.00000046 & 7.37 & 0.109 & 0.23 \\
\hline \multicolumn{8}{|c|}{ Temora-II 2006} \\
\hline 1.1 & 7 & 2.38 & 0.00202263 & 0.00000038 & 7.65 & 0.091 & 0.19 \\
\hline 2.1 & 8 & 2.39 & 0.00202333 & 0.00000037 & 8.00 & 0.087 & 0.18 \\
\hline 3.1 & 15 & 2.39 & 0.00202285 & 0.00000047 & 7.59 & 0.111 & 0.23 \\
\hline 4.1 & 16 & 2.39 & 0.00202275 & 0.00000041 & 7.54 & 0.097 & 0.20 \\
\hline 5.1 & 23 & 2.39 & 0.00202354 & 0.00000041 & 7.95 & 0.097 & 0.20 \\
\hline 6.1 & 24 & 2.37 & 0.00202299 & 0.00000026 & 7.67 & 0.062 & 0.13 \\
\hline 7.1 & 31 & 2.37 & 0.00202330 & 0.00000041 & 7.96 & 0.097 & 0.20 \\
\hline
\end{tabular}




\begin{tabular}{|c|c|c|c|c|c|c|c|}
\hline Grain.spot & $\begin{array}{r}\text { Acquisition } \\
\text { order }\end{array}$ & $\begin{array}{l}{ }^{16} \mathrm{O} \text { count } \\
\text { rate }(\mathrm{GHz})\end{array}$ & ${ }^{18} \mathrm{O}^{16} \mathrm{O}^{1}$ & $\pm c 95 \% \%^{2}$ & $\begin{array}{r}\delta^{18} \mathrm{O}_{\text {smow }}{ }^{3} \\
(\%)\end{array}$ & $\begin{array}{l} \pm 1 \sigma \\
(\% \circ)\end{array}$ & $\begin{array}{r} \pm c 95 \% \%^{2} \\
(\%)\end{array}$ \\
\hline 8.1 & 32 & 2.37 & 0.00202287 & 0.00000036 & 7.75 & 0.086 & 0.18 \\
\hline 9.1 & 39 & 2.36 & 0.00202347 & 0.00000033 & 8.16 & 0.079 & 0.16 \\
\hline 10.1 & 40 & 2.36 & 0.00202325 & 0.00000028 & 8.05 & 0.066 & 0.14 \\
\hline 11.1 & 47 & 2.35 & 0.00202304 & 0.00000035 & 7.80 & 0.083 & 0.17 \\
\hline 12.1 & 48 & 2.35 & 0.00202327 & 0.00000039 & 7.91 & 0.091 & 0.19 \\
\hline 13.1 & 105 & 2.11 & 0.00202351 & 0.00000044 & 8.21 & 0.104 & 0.22 \\
\hline 14.1 & 106 & 2.12 & 0.00202312 & 0.00000039 & 8.02 & 0.091 & 0.19 \\
\hline 15.1 & 113 & 2.11 & 0.00202375 & 0.00000049 & 8.26 & 0.116 & 0.24 \\
\hline 16.1 & 114 & 2.11 & 0.00202320 & 0.00000034 & 7.99 & 0.079 & 0.17 \\
\hline 17.1 & 121 & 2.10 & 0.00202351 & 0.00000037 & 8.08 & 0.088 & 0.18 \\
\hline 18.1 & 122 & 2.10 & 0.00202370 & 0.00000047 & 8.17 & 0.111 & 0.23 \\
\hline 19.1 & 129 & 2.10 & 0.00202364 & 0.00000056 & 8.10 & 0.132 & 0.28 \\
\hline 20.1 & 130 & 2.09 & 0.00202334 & 0.00000045 & 7.96 & 0.106 & 0.22 \\
\hline \multicolumn{8}{|c|}{ Temora-2 2011} \\
\hline 1.1 & 53 & 2.33 & 0.00202190 & 0.00000040 & 7.37 & 0.094 & 0.20 \\
\hline 2.1 & 54 & 2.33 & 0.00202204 & 0.00000032 & 7.44 & 0.077 & 0.16 \\
\hline 3.1 & 61 & 2.32 & 0.00202181 & 0.00000040 & 7.25 & 0.095 & 0.20 \\
\hline 4.1 & 62 & 2.32 & 0.00202177 & 0.00000039 & 7.23 & 0.092 & 0.19 \\
\hline 5.1 & 69 & 2.31 & 0.00202189 & 0.00000032 & 7.25 & 0.076 & 0.16 \\
\hline 6.1 & 70 & 2.32 & 0.00202197 & 0.00000036 & 7.29 & 0.085 & 0.18 \\
\hline 7.1 & 77 & 2.32 & 0.00202167 & 0.00000035 & 7.11 & 0.083 & 0.17 \\
\hline 8.1 & 78 & 2.32 & 0.00202215 & 0.00000044 & 7.35 & 0.104 & 0.22 \\
\hline 9.1 & 85 & 2.33 & 0.00202237 & 0.00000035 & 7.48 & 0.084 & 0.17 \\
\hline 10.1 & 86 & 2.33 & 0.00202207 & 0.00000047 & 7.34 & 0.111 & 0.23 \\
\hline 11.1 & 93 & 2.33 & 0.00202241 & 0.00000052 & 7.67 & 0.122 & 0.25 \\
\hline 12.1 & 94 & 2.33 & 0.00202176 & 0.00000035 & 7.34 & 0.084 & 0.17 \\
\hline 13.1 & 135 & 2.08 & 0.00202213 & 0.00000042 & 7.32 & 0.100 & 0.21 \\
\hline 14.1 & 136 & 2.08 & 0.00202206 & 0.00000035 & 7.28 & 0.084 & 0.18 \\
\hline 15.1 & 143 & 2.06 & 0.00202202 & 0.00000042 & 7.19 & 0.100 & 0.21 \\
\hline 16.1 & 144 & 2.06 & 0.00202200 & 0.00000037 & 7.18 & 0.087 & 0.18 \\
\hline 17.1 & 151 & 2.06 & 0.00202221 & 0.00000041 & 7.31 & 0.097 & 0.20 \\
\hline
\end{tabular}




\begin{tabular}{|c|c|c|c|c|c|c|c|}
\hline Grain.spot & $\begin{array}{r}\text { Acquisition } \\
\text { order }\end{array}$ & $\begin{array}{l}{ }^{16} \mathrm{O} \text { count } \\
\text { rate }(\mathrm{GHz})\end{array}$ & ${ }^{18} \mathrm{O} /{ }^{16} \mathrm{O}^{1}$ & $\pm c 95 \%^{2}$ & $\begin{array}{r}\delta^{18} \mathrm{O}_{\text {smow }}{ }^{3} \\
(\% 0)\end{array}$ & $\begin{array}{l} \pm 1 \sigma \\
(\% \circ)\end{array}$ & $\begin{array}{r} \pm c 95 \% \%^{2} \\
(\%)\end{array}$ \\
\hline 18.1 & 152 & 2.06 & 0.00202203 & 0.00000042 & 7.22 & 0.099 & 0.21 \\
\hline 19.1 & 159 & 2.05 & 0.00202227 & 0.00000038 & 7.38 & 0.091 & 0.19 \\
\hline 20.1 & 160 & 2.05 & 0.00202227 & 0.00000024 & 7.38 & 0.056 & 0.12 \\
\hline
\end{tabular}

\section{Temora-2 2011 HIP}

\begin{tabular}{|c|c|c|c|c|c|c|c|}
\hline 1.1 & 5 & 2.39 & 0.00202182 & 0.00000030 & 7.25 & 0.072 & 0.15 \\
\hline 2.1 & 6 & 2.39 & 0.00202175 & 0.00000057 & 7.21 & 0.134 & 0.28 \\
\hline 3.1 & 13 & 2.38 & 0.00202193 & 0.00000040 & 7.13 & 0.094 & 0.20 \\
\hline 4.1 & 14 & 2.38 & 0.00202237 & 0.00000033 & 7.35 & 0.077 & 0.16 \\
\hline 5.1 & 21 & 2.38 & 0.00202215 & 0.00000039 & 7.25 & 0.091 & 0.19 \\
\hline 6.1 & 22 & 2.38 & 0.00202176 & 0.00000028 & 7.06 & 0.066 & 0.14 \\
\hline 7.1 & 29 & 2.37 & 0.00202253 & 0.00000040 & 7.58 & 0.095 & 0.20 \\
\hline 8.1 & 30 & 2.36 & 0.00202190 & 0.00000053 & 7.27 & 0.126 & 0.26 \\
\hline 9.1 & 37 & 2.37 & 0.00202235 & 0.00000044 & 7.60 & 0.103 & 0.22 \\
\hline 10.1 & 38 & 2.37 & 0.00202229 & 0.00000044 & 7.57 & 0.103 & 0.22 \\
\hline 11.1 & 45 & 2.35 & 0.00202193 & 0.00000029 & 7.24 & 0.069 & 0.14 \\
\hline 12.1 & 46 & 2.36 & 0.00202192 & 0.00000045 & 7.24 & 0.105 & 0.22 \\
\hline 13.1 & 103 & 2.11 & 0.00202211 & 0.00000052 & 7.52 & 0.122 & 0.26 \\
\hline 14.1 & 104 & 2.12 & 0.00202234 & 0.00000032 & 7.63 & 0.076 & 0.16 \\
\hline 15.1 & 111 & 2.11 & 0.00202197 & 0.00000044 & 7.38 & 0.103 & 0.22 \\
\hline 16.1 & 112 & 2.11 & 0.00202208 & 0.00000029 & 7.43 & 0.070 & 0.15 \\
\hline 17.1 & 119 & 2.11 & 0.00202255 & 0.00000054 & 7.60 & 0.129 & 0.27 \\
\hline 18.1 & 120 & 2.10 & 0.00202217 & 0.00000053 & 7.41 & 0.124 & 0.26 \\
\hline 19.1 & 127 & 2.09 & 0.00202196 & 0.00000043 & 7.26 & 0.102 & 0.21 \\
\hline 20.1 & 128 & 2.10 & 0.00202207 & 0.00000039 & 7.32 & 0.093 & 0.19 \\
\hline \multicolumn{8}{|c|}{ Temora-2 2013} \\
\hline 1.1 & 51 & 2.34 & 0.00202199 & 0.00000038 & 7.41 & 0.089 & 0.19 \\
\hline 2.1 & 52 & 2.33 & 0.00202173 & 0.00000036 & 7.28 & 0.086 & 0.18 \\
\hline 3.1 & 59 & 2.33 & 0.00202237 & 0.00000040 & 7.53 & 0.095 & 0.20 \\
\hline 4.1 & 60 & 2.33 & 0.00202225 & 0.00000032 & 7.47 & 0.077 & 0.16 \\
\hline 5.1 & 67 & 2.33 & 0.00202224 & 0.00000027 & 7.43 & 0.064 & 0.13 \\
\hline 6.1 & 68 & 2.33 & 0.00202178 & 0.00000036 & 7.20 & 0.086 & 0.18 \\
\hline
\end{tabular}




\begin{tabular}{|c|c|c|c|c|c|c|c|}
\hline Grain.spot & $\begin{array}{r}\text { Acquisition } \\
\text { order }\end{array}$ & $\begin{array}{l}{ }^{16} \mathrm{O} \text { count } \\
\text { rate }(\mathrm{GHz})\end{array}$ & ${ }^{18} \mathrm{O} /{ }^{16} \mathrm{O}^{1}$ & $\pm c 95 \%{ }^{2}$ & $\begin{array}{r}\delta^{18} \mathrm{O}_{\text {sMow }}{ }^{3} \\
(\% 0)\end{array}$ & $\begin{array}{l} \pm 1 \sigma \\
(\% \circ)\end{array}$ & $\begin{array}{r} \pm c 95 \% 2 \\
(\% 0)\end{array}$ \\
\hline 7.1 & 75 & 2.34 & 0.00202229 & 0.00000039 & 7.42 & 0.093 & 0.19 \\
\hline 8.1 & 76 & 2.33 & 0.00202228 & 0.00000047 & 7.41 & 0.112 & 0.23 \\
\hline 9.1 & 83 & 2.32 & 0.00202209 & 0.00000051 & 7.35 & 0.121 & 0.25 \\
\hline 10.1 & 84 & 2.32 & 0.00202171 & 0.00000041 & 7.15 & 0.098 & 0.20 \\
\hline 11.1 & 91 & 2.33 & 0.00202239 & 0.00000046 & 7.66 & 0.108 & 0.23 \\
\hline 12.1 & 92 & 2.33 & 0.00202182 & 0.00000059 & 7.37 & 0.139 & 0.29 \\
\hline 13.1 & 133 & 2.09 & 0.00202250 & 0.00000041 & 7.51 & 0.098 & 0.20 \\
\hline 14.1 & 134 & 2.08 & 0.00202212 & 0.00000037 & 7.32 & 0.087 & 0.18 \\
\hline 15.1 & 141 & 2.07 & 0.00202247 & 0.00000056 & 7.42 & 0.132 & 0.27 \\
\hline 16.1 & 142 & 2.07 & 0.00202184 & 0.00000039 & 7.11 & 0.093 & 0.19 \\
\hline 17.1 & 149 & 2.07 & 0.00202265 & 0.00000040 & 7.53 & 0.095 & 0.20 \\
\hline 18.1 & 150 & 2.07 & 0.00202201 & 0.00000056 & 7.21 & 0.132 & 0.28 \\
\hline 19.1 & 157 & 2.06 & 0.00202221 & 0.00000037 & 7.36 & 0.087 & 0.18 \\
\hline 20.1 & 158 & 2.06 & 0.00202196 & 0.00000049 & 7.23 & 0.116 & 0.24 \\
\hline
\end{tabular}

1. HIP: Raw intensity ratios corrected for background and detector gain.

2. $95 \%$ confidence interval includes the t-distribution factor for replicate cycles.

3. Corrected for instrumental mass fractionation (IMF) using the average of the IMF factors determined from the HIP 91500 (normalised to $\delta^{18} O_{\text {SMOW }}=9.86 \%$ ) and HIP AS3 (normalised to $\delta^{18} O_{S M O W}=5.34 \%$ ) datasets. 


\section{Appendix B Oxygen-isotope analytical data: SHRIMP SI (ANU)}

Appendix Table B.1 SHRIMP SI (ANU) analyses of reference zircons 91500 and AS3. IMF correction factors were calculated from both datasets, and the average used to perform the IMF correction on analyses of the five Temora zircon aliquots (Temora-1, Temora-Il 2006, Temora-2 2011, Temora-2 2011 HIP, and Temora-2 2013).

\begin{tabular}{|c|c|c|c|c|c|c|c|}
\hline Grain.spot & $\begin{array}{r}\text { Acquisition } \\
\text { order }\end{array}$ & $\begin{array}{l}{ }^{16} \mathrm{O} \text { count } \\
\text { rate }(\mathrm{GHz})\end{array}$ & ${ }^{18} \mathrm{O} /{ }^{16} \mathrm{O}^{1}$ & $\pm c 95 \% 2$ & $\begin{array}{r}\delta^{18} \mathrm{O}_{\text {sMow }}{ }^{3} \\
(\% 0)\end{array}$ & $\begin{array}{l} \pm 1 \sigma \\
(\%)\end{array}$ & $\begin{array}{r} \pm c 95 \% 2 \\
(\% 0)\end{array}$ \\
\hline \multicolumn{8}{|l|}{91500} \\
\hline 1.1 & 1 & 1.82 & 0.00203937 & 0.00000037 & 10.27 & 0.071 & 0.18 \\
\hline 2.1 & 3 & 1.83 & 0.00203827 & 0.00000037 & 9.72 & 0.070 & 0.18 \\
\hline 3.1 & 8 & 1.75 & 0.00203831 & 0.00000049 & 9.74 & 0.094 & 0.24 \\
\hline 4.1 & 14 & 1.75 & 0.00203896 & 0.00000023 & 10.07 & 0.043 & 0.11 \\
\hline 5.1 & 20 & 1.74 & 0.00203851 & 0.00000031 & 9.84 & 0.059 & 0.15 \\
\hline 6.1 & 26 & 1.87 & 0.00203944 & 0.00000031 & 10.30 & 0.058 & 0.15 \\
\hline 7.1 & 34 & 1.85 & 0.00203803 & 0.00000023 & 9.60 & 0.044 & 0.11 \\
\hline 8.1 & 42 & 1.80 & 0.00203884 & 0.00000030 & 10.01 & 0.058 & 0.15 \\
\hline 9.1 & 50 & 1.85 & 0.00203899 & 0.00000036 & 10.08 & 0.069 & 0.18 \\
\hline 10.1 & 58 & 1.84 & 0.00203848 & 0.00000032 & 9.83 & 0.061 & 0.16 \\
\hline 11.1 & 65 & 1.83 & 0.00203945 & 0.00000042 & 10.31 & 0.079 & 0.20 \\
\hline 12.1 & 72 & 1.78 & 0.00203805 & 0.00000042 & 9.62 & 0.081 & 0.21 \\
\hline 13.1 & 79 & 1.79 & 0.00203855 & 0.00000032 & 9.86 & 0.060 & 0.15 \\
\hline 14.1 & 86 & 1.82 & 0.00203891 & 0.00000031 & 10.04 & 0.059 & 0.15 \\
\hline 15.1 & 93 & 1.81 & 0.00203840 & 0.00000018 & 9.79 & 0.034 & 0.09 \\
\hline 16.1 & 100 & 1.82 & 0.00203872 & 0.00000032 & 9.95 & 0.060 & 0.16 \\
\hline 17.1 & 107 & 1.81 & 0.00203909 & 0.00000032 & 10.13 & 0.062 & 0.16 \\
\hline 18.1 & 114 & 1.80 & 0.00203866 & 0.00000045 & 9.92 & 0.086 & 0.22 \\
\hline 19.1 & 121 & 1.85 & 0.00203892 & 0.00000032 & 10.05 & 0.061 & 0.16 \\
\hline 20.1 & 128 & 1.79 & 0.00203931 & 0.00000038 & 10.24 & 0.072 & 0.18 \\
\hline 21.1 & 135 & 1.83 & 0.00203869 & 0.00000027 & 9.93 & 0.052 & 0.13 \\
\hline 22.1 & 142 & 1.83 & 0.00203899 & 0.00000026 & 10.08 & 0.050 & 0.13 \\
\hline
\end{tabular}

AS3

\begin{tabular}{|l|r|r|r|r|r|r|r|}
\hline 1.1 & 1.76 & 0.00202830 & 0.00000041 & 4.79 & 0.078 & 0.20 \\
\hline
\end{tabular}




\begin{tabular}{|c|c|c|c|c|c|c|c|}
\hline Grain.spot & $\begin{array}{r}\text { Acquisition } \\
\text { order }\end{array}$ & $\begin{array}{l}{ }^{16} \mathrm{O} \text { count } \\
\text { rate }(\mathrm{GHz})\end{array}$ & ${ }^{18} \mathrm{O}^{16} \mathrm{O}^{1}$ & $\pm c 95 \% \%^{2}$ & $\begin{array}{r}\delta^{18} \mathrm{O}_{\text {sMow }}{ }^{3} \\
(\% 0)\end{array}$ & $\begin{array}{l} \pm 1 \sigma \\
(\% \circ)\end{array}$ & $\begin{array}{r} \pm c 95 \%{ }^{2} \\
(\% 0)\end{array}$ \\
\hline 2.1 & 13 & 1.80 & 0.00202940 & 0.00000020 & 5.33 & 0.038 & 0.10 \\
\hline 3.1 & 19 & 1.79 & 0.00202942 & 0.00000027 & 5.34 & 0.052 & 0.13 \\
\hline 4.1 & 25 & 1.79 & 0.00202936 & 0.00000026 & 5.31 & 0.049 & 0.13 \\
\hline 5.1 & 33 & 1.81 & 0.00202995 & 0.00000031 & 5.60 & 0.059 & 0.15 \\
\hline 6.1 & 41 & 1.81 & 0.00202946 & 0.00000029 & 5.36 & 0.055 & 0.14 \\
\hline 7.1 & 49 & 1.80 & 0.00202857 & 0.00000041 & 4.92 & 0.078 & 0.20 \\
\hline 8.1 & 57 & 1.79 & 0.00202906 & 0.00000022 & 5.16 & 0.042 & 0.11 \\
\hline 9.1 & 64 & 1.81 & 0.00202949 & 0.00000042 & 5.37 & 0.080 & 0.21 \\
\hline 10.1 & 71 & 1.81 & 0.00202943 & 0.00000050 & 5.35 & 0.096 & 0.25 \\
\hline 11.1 & 78 & 1.81 & 0.00202963 & 0.00000028 & 5.44 & 0.054 & 0.14 \\
\hline 12.1 & 85 & 1.79 & 0.00202877 & 0.00000028 & 5.02 & 0.053 & 0.14 \\
\hline 12.2 & 92 & 1.73 & 0.00202894 & 0.00000050 & 5.10 & 0.095 & 0.24 \\
\hline 13.1 & 99 & 1.74 & 0.00202874 & 0.00000044 & 5.00 & 0.085 & 0.22 \\
\hline 14.1 & 106 & 1.85 & 0.00202986 & 0.00000042 & 5.56 & 0.081 & 0.21 \\
\hline 15.1 & 113 & 1.82 & 0.00202925 & 0.00000038 & 5.26 & 0.073 & 0.19 \\
\hline 16.1 & 120 & 1.82 & 0.00202955 & 0.00000029 & 5.40 & 0.056 & 0.14 \\
\hline 17.1 & 127 & 1.85 & 0.00202880 & 0.00000024 & 5.04 & 0.046 & 0.12 \\
\hline 18.1 & 134 & 1.81 & 0.00202877 & 0.00000059 & 5.02 & 0.112 & 0.29 \\
\hline 19.1 & 141 & 1.79 & 0.00202866 & 0.00000053 & 4.96 & 0.101 & 0.26 \\
\hline
\end{tabular}

1. ANU: Raw intensity ratios corrected for electron-induced secondary ion emission.

2. $95 \%$ confidence interval includes the $t$-distribution factor for replicate cycles.

3. Corrected for instrumental mass fractionation (IMF) using the average of the IMF factors determined from the ANU 91500 (normalised to $\delta^{18} \mathrm{O}_{\text {SMOW }}=9.86 \%$ ) and ANU AS3 (normalised to $\delta^{18} \mathrm{O}_{\text {SMOW }}=5.34 \%$ ) datasets. 
Appendix Table B.2 SHRIMP SI (ANU) analyses of five Temora zircon aliquots (Temora-1, Temora-II 2006, Temora-2 2011, Temora-2 2011 HIP, and Temora-2 2013) as unknowns, IMF-corrected using the average of the IMF factors determined from the two reference zircons 91500 and AS3.

\begin{tabular}{|c|c|c|c|c|c|c|c|}
\hline Grain.spot & $\begin{array}{r}\text { Acquisition } \\
\text { order }\end{array}$ & $\begin{array}{l}{ }^{16} \mathrm{O} \text { count } \\
\text { rate (GHz) }\end{array}$ & ${ }^{18} \mathrm{O}^{16} \mathrm{O}^{1}$ & $\pm c 95 \%{ }^{2}$ & $\begin{array}{r}\delta^{18} \mathbf{O}_{\text {smow }}{ }^{3} \\
(\%)\end{array}$ & $\begin{array}{l} \pm 1 \sigma \\
(\%)\end{array}$ & $\begin{array}{r} \pm c 95 \%{ }^{2} \\
(\%)\end{array}$ \\
\hline \multicolumn{8}{|l|}{ Temora-1 } \\
\hline 1.1 & 2 & 1.83 & 0.00203410 & 0.00000030 & 7.66 & 0.056 & 0.14 \\
\hline 2.1 & 9 & 1.76 & 0.00203373 & 0.00000021 & 7.48 & 0.041 & 0.11 \\
\hline 3.1 & 15 & 1.77 & 0.00203393 & 0.00000030 & 7.57 & 0.057 & 0.15 \\
\hline 4.1 & 21 & 1.74 & 0.00203503 & 0.00000025 & 8.12 & 0.048 & 0.12 \\
\hline 5.1 & 27 & 1.82 & 0.00203377 & 0.00000034 & 7.49 & 0.064 & 0.16 \\
\hline 6.1 & 35 & 1.84 & 0.00203367 & 0.00000024 & 7.44 & 0.046 & 0.12 \\
\hline 7.1 & 43 & 1.83 & 0.00203397 & 0.00000025 & 7.59 & 0.047 & 0.12 \\
\hline 8.1 & 51 & 1.84 & 0.00203434 & 0.00000044 & 7.78 & 0.083 & 0.21 \\
\hline 9.1 & 59 & 1.81 & 0.00203407 & 0.00000029 & 7.64 & 0.056 & 0.14 \\
\hline 10.1 & 66 & 1.81 & 0.00203374 & 0.00000027 & 7.48 & 0.052 & 0.13 \\
\hline 1.2 & 73 & 1.83 & 0.00203484 & 0.00000026 & 8.02 & 0.050 & 0.13 \\
\hline 2.2 & 80 & 1.82 & 0.00203360 & 0.00000039 & 7.41 & 0.075 & 0.19 \\
\hline 3.2 & 87 & 1.82 & 0.00203349 & 0.00000023 & 7.35 & 0.044 & 0.11 \\
\hline 4.2 & 94 & 1.82 & 0.00203371 & 0.00000028 & 7.47 & 0.053 & 0.14 \\
\hline 5.2 & 101 & 1.81 & 0.00203399 & 0.00000027 & 7.60 & 0.052 & 0.13 \\
\hline 6.2 & 108 & 1.81 & 0.00203310 & 0.00000046 & 7.16 & 0.088 & 0.23 \\
\hline 7.2 & 115 & 1.81 & 0.00203418 & 0.00000040 & 7.70 & 0.076 & 0.19 \\
\hline 8.2 & 122 & 1.81 & 0.00203368 & 0.00000049 & 7.45 & 0.093 & 0.24 \\
\hline 9.2 & 129 & 1.80 & 0.00203326 & 0.00000038 & 7.24 & 0.072 & 0.19 \\
\hline 10.2 & 136 & 1.80 & 0.00203377 & 0.00000031 & 7.49 & 0.059 & 0.15 \\
\hline
\end{tabular}

\section{Temora-II 2006}

\begin{tabular}{|c|c|c|c|c|c|c|c|}
\hline 1.1 & 6 & 1.78 & 0.00203501 & 0.00000046 & 8.11 & 0.087 & 0.22 \\
\hline 2.1 & 12 & 1.75 & 0.00203452 & 0.00000048 & 7.87 & 0.092 & 0.24 \\
\hline 3.1 & 18 & 1.76 & 0.00203523 & 0.00000035 & 8.22 & 0.067 & 0.17 \\
\hline 4.1 & 24 & 1.87 & 0.00203512 & 0.00000018 & 8.17 & 0.035 & 0.09 \\
\hline 5.1 & 30 & 1.86 & 0.00203437 & 0.00000025 & 7.79 & 0.047 & 0.12 \\
\hline 6.1 & 38 & 1.81 & 0.00203594 & 0.00000031 & 8.57 & 0.060 & 0.15 \\
\hline 7.1 & 46 & 1.81 & 0.00203483 & 0.00000045 & 8.02 & 0.087 & 0.22 \\
\hline
\end{tabular}




\begin{tabular}{|c|c|c|c|c|c|c|c|}
\hline Grain.spot & $\begin{array}{r}\text { Acquisition } \\
\text { order }\end{array}$ & $\begin{array}{l}{ }^{16} \mathrm{O} \text { count } \\
\text { rate }(\mathrm{GHz})\end{array}$ & ${ }^{18} \mathrm{O}^{16} \mathrm{O}^{1}$ & $\pm c 95 \%^{2}$ & $\begin{array}{r}\delta^{18} O_{\text {smow }}{ }^{3} \\
(\% 0)\end{array}$ & $\begin{array}{l} \pm 1 \sigma \\
(\% \circ)\end{array}$ & $\begin{array}{r} \pm c 95 \%{ }^{2} \\
(\%)\end{array}$ \\
\hline 8.1 & 54 & 1.82 & 0.00203488 & 0.00000044 & 8.04 & 0.084 & 0.22 \\
\hline 9.1 & 62 & 1.78 & 0.00203423 & 0.00000076 & 7.72 & 0.144 & 0.37 \\
\hline 10.1 & 69 & 1.81 & 0.00203428 & 0.00000032 & 7.75 & 0.061 & 0.16 \\
\hline 1.2 & 76 & 1.80 & 0.00203543 & 0.00000043 & 8.32 & 0.082 & 0.21 \\
\hline 2.2 & 83 & 1.80 & 0.00203480 & 0.00000049 & 8.01 & 0.094 & 0.24 \\
\hline 3.2 & 90 & 1.82 & 0.00203505 & 0.00000026 & 8.13 & 0.049 & 0.13 \\
\hline 4.2 & 97 & 1.81 & 0.00203469 & 0.00000024 & 7.95 & 0.045 & 0.12 \\
\hline 5.2 & 104 & 1.79 & 0.00203529 & 0.00000060 & 8.25 & 0.115 & 0.29 \\
\hline 6.2 & 111 & 1.81 & 0.00203522 & 0.00000028 & 8.22 & 0.054 & 0.14 \\
\hline 7.2 & 118 & 1.79 & 0.00203476 & 0.00000031 & 7.98 & 0.058 & 0.15 \\
\hline 8.2 & 125 & 1.81 & 0.00203453 & 0.00000040 & 7.87 & 0.077 & 0.20 \\
\hline 9.2 & 132 & 1.80 & 0.00203418 & 0.00000039 & 7.70 & 0.074 & 0.19 \\
\hline 10.2 & 139 & 1.81 & 0.00203425 & 0.00000051 & 7.73 & 0.098 & 0.25 \\
\hline \multicolumn{8}{|c|}{ Temora-2 2011} \\
\hline 1.1 & 4 & 1.80 & 0.00203374 & 0.00000070 & 7.48 & 0.135 & 0.35 \\
\hline 2.1 & 10 & 1.77 & 0.00203366 & 0.00000035 & 7.44 & 0.067 & 0.17 \\
\hline 3.1 & 16 & 1.74 & 0.00203310 & 0.00000025 & 7.17 & 0.047 & 0.12 \\
\hline 4.1 & 22 & 1.74 & 0.00203286 & 0.00000059 & 7.04 & 0.113 & 0.29 \\
\hline 5.1 & 28 & 1.81 & 0.00203355 & 0.00000030 & 7.39 & 0.057 & 0.15 \\
\hline 6.1 & 36 & 1.85 & 0.00203345 & 0.00000051 & 7.33 & 0.098 & 0.25 \\
\hline 7.1 & 44 & 1.82 & 0.00203330 & 0.00000029 & 7.26 & 0.055 & 0.14 \\
\hline 8.1 & 52 & 1.83 & 0.00203341 & 0.00000031 & 7.32 & 0.059 & 0.15 \\
\hline 9.1 & 60 & 1.80 & 0.00203288 & 0.00000024 & 7.05 & 0.046 & 0.12 \\
\hline 10.1 & 67 & 1.80 & 0.00203338 & 0.00000024 & 7.30 & 0.046 & 0.12 \\
\hline 1.2 & 74 & 1.82 & 0.00203413 & 0.00000033 & 7.67 & 0.062 & 0.16 \\
\hline 2.2 & 81 & 1.81 & 0.00203337 & 0.00000038 & 7.30 & 0.073 & 0.19 \\
\hline 3.2 & 88 & 1.81 & 0.00203386 & 0.00000032 & 7.54 & 0.060 & 0.15 \\
\hline 4.2 & 95 & 1.80 & 0.00203320 & 0.00000034 & 7.21 & 0.065 & 0.17 \\
\hline 5.2 & 102 & 1.81 & 0.00203347 & 0.00000031 & 7.35 & 0.058 & 0.15 \\
\hline 6.2 & 109 & 1.82 & 0.00203439 & 0.00000025 & 7.80 & 0.047 & 0.12 \\
\hline 7.2 & 116 & 1.79 & 0.00203328 & 0.00000038 & 7.25 & 0.073 & 0.19 \\
\hline
\end{tabular}




\begin{tabular}{|c|c|c|c|c|c|c|c|}
\hline Grain.spot & $\begin{array}{r}\text { Acquisition } \\
\text { order }\end{array}$ & $\begin{array}{l}{ }^{16} \mathrm{O} \text { count } \\
\text { rate }(\mathrm{GHz})\end{array}$ & ${ }^{18} \mathrm{O}^{16} \mathrm{O}^{1}$ & $\pm c 95 \%^{2}$ & $\begin{array}{r}\delta^{18} \mathbf{O}_{\text {smow }}{ }^{3} \\
(\% \circ)\end{array}$ & $\begin{array}{l} \pm 1 \sigma \\
(\%)\end{array}$ & $\begin{array}{r} \pm c 95 \% \%^{2} \\
(\%)\end{array}$ \\
\hline 8.2 & 123 & 1.80 & 0.00203263 & 0.00000047 & 6.93 & 0.091 & 0.23 \\
\hline 9.2 & 130 & 1.80 & 0.00203301 & 0.00000042 & 7.12 & 0.081 & 0.21 \\
\hline 10.2 & 137 & 1.80 & 0.00203345 & 0.00000055 & 7.34 & 0.106 & 0.27 \\
\hline
\end{tabular}

\section{Temora-2 2011 HIP}

\begin{tabular}{|c|c|c|c|c|c|c|c|}
\hline 1.1 & 31 & 1.85 & 0.00203343 & 0.00000024 & 7.33 & 0.045 & 0.12 \\
\hline 2.1 & 32 & 1.84 & 0.00203338 & 0.00000031 & 7.30 & 0.060 & 0.15 \\
\hline 3.1 & 39 & 1.82 & 0.00203354 & 0.00000025 & 7.38 & 0.048 & 0.12 \\
\hline 4.1 & 40 & 1.81 & 0.00203274 & 0.00000024 & 6.99 & 0.047 & 0.12 \\
\hline 5.1 & 47 & 1.82 & 0.00203375 & 0.00000055 & 7.49 & 0.105 & 0.27 \\
\hline 6.1 & 48 & 1.87 & 0.00203375 & 0.00000057 & 7.48 & 0.110 & 0.28 \\
\hline 7.1 & 55 & 1.84 & 0.00203381 & 0.00000055 & 7.52 & 0.104 & 0.27 \\
\hline 8.1 & 56 & 1.83 & 0.00203381 & 0.00000031 & 7.52 & 0.059 & 0.15 \\
\hline 9.1 & 63 & 1.81 & 0.00203365 & 0.00000047 & 7.44 & 0.090 & 0.23 \\
\hline 1.2 & 70 & 1.80 & 0.00203350 & 0.00000055 & 7.36 & 0.104 & 0.27 \\
\hline 1.3 & 77 & 1.80 & 0.00203422 & 0.00000036 & 7.72 & 0.070 & 0.18 \\
\hline 1.4 & 84 & 1.80 & 0.00203383 & 0.00000025 & 7.52 & 0.047 & 0.12 \\
\hline 2.2 & 91 & 1.79 & 0.00203326 & 0.00000062 & 7.24 & 0.118 & 0.30 \\
\hline 3.2 & 98 & 1.80 & 0.00203332 & 0.00000028 & 7.27 & 0.054 & 0.14 \\
\hline 4.2 & 105 & 1.79 & 0.00203293 & 0.00000041 & 7.08 & 0.078 & 0.20 \\
\hline 5.2 & 112 & 1.80 & 0.00203297 & 0.00000021 & 7.10 & 0.039 & 0.10 \\
\hline 6.2 & 119 & 1.80 & 0.00203337 & 0.00000031 & 7.30 & 0.059 & 0.15 \\
\hline 7.2 & 126 & 1.82 & 0.00203286 & 0.00000040 & 7.04 & 0.076 & 0.19 \\
\hline 8.2 & 133 & 1.80 & 0.00203318 & 0.00000047 & 7.20 & 0.089 & 0.23 \\
\hline 9.2 & 140 & 1.79 & 0.00203297 & 0.00000030 & 7.10 & 0.058 & 0.15 \\
\hline \multicolumn{8}{|c|}{ Temora-2 2013} \\
\hline 1.1 & 5 & 1.79 & 0.00203370 & 0.00000025 & 7.46 & 0.048 & 0.12 \\
\hline 2.1 & 11 & 1.75 & 0.00203331 & 0.00000027 & 7.27 & 0.052 & 0.13 \\
\hline 3.1 & 17 & 1.76 & 0.00203350 & 0.00000037 & 7.36 & 0.071 & 0.18 \\
\hline 4.1 & 23 & 1.73 & 0.00203358 & 0.00000033 & 7.40 & 0.064 & 0.16 \\
\hline 5.1 & 29 & 1.82 & 0.00203320 & 0.00000035 & 7.21 & 0.066 & 0.17 \\
\hline 6.1 & 37 & 1.85 & 0.00203344 & 0.00000030 & 7.33 & 0.057 & 0.15 \\
\hline
\end{tabular}




\begin{tabular}{|c|c|c|c|c|c|c|c|}
\hline Grain.spot & $\begin{array}{r}\text { Acquisition } \\
\text { order }\end{array}$ & $\begin{array}{l}{ }^{16} \mathrm{O} \text { count } \\
\text { rate (GHz) }\end{array}$ & ${ }^{18} \mathrm{O} /{ }^{16} \mathrm{O}^{1}$ & $\pm c 95 \%{ }^{2}$ & $\begin{array}{r}\delta^{18} O_{\text {SMow }}{ }^{3} \\
(\% 0)\end{array}$ & $\begin{array}{l} \pm 1 \sigma \\
(\% \circ)\end{array}$ & $\begin{array}{r} \pm c 95 \% \%^{2} \\
(\% \circ)\end{array}$ \\
\hline 7.1 & 45 & 1.83 & 0.00203386 & 0.00000044 & 7.54 & 0.085 & 0.22 \\
\hline 8.1 & 53 & 1.84 & 0.00203352 & 0.00000037 & 7.37 & 0.070 & 0.18 \\
\hline 9.1 & 61 & 1.81 & 0.00203381 & 0.00000024 & 7.51 & 0.046 & 0.12 \\
\hline 10.1 & 68 & 1.81 & 0.00203340 & 0.00000048 & 7.31 & 0.093 & 0.24 \\
\hline 1.2 & 75 & 1.81 & 0.00203398 & 0.00000039 & 7.60 & 0.075 & 0.19 \\
\hline 2.2 & 82 & 1.80 & 0.00203382 & 0.00000019 & 7.52 & 0.037 & 0.09 \\
\hline 3.2 & 89 & 1.80 & 0.00203349 & 0.00000043 & 7.36 & 0.082 & 0.21 \\
\hline 4.2 & 96 & 1.78 & 0.00203370 & 0.00000053 & 7.46 & 0.102 & 0.26 \\
\hline 5.2 & 103 & 1.80 & 0.00203333 & 0.00000026 & 7.28 & 0.050 & 0.13 \\
\hline 6.2 & 110 & 1.82 & 0.00203342 & 0.00000025 & 7.32 & 0.048 & 0.12 \\
\hline 7.2 & 117 & 1.81 & 0.00203392 & 0.00000031 & 7.57 & 0.059 & 0.15 \\
\hline 8.2 & 124 & 1.81 & 0.00203341 & 0.00000026 & 7.32 & 0.050 & 0.13 \\
\hline 9.2 & 131 & 1.81 & 0.00203304 & 0.00000050 & 7.14 & 0.095 & 0.24 \\
\hline 10.2 & 138 & 1.81 & 0.00203285 & 0.00000037 & 7.04 & 0.070 & 0.18 \\
\hline
\end{tabular}

1. ANU: Raw intensity ratios corrected for electron-induced secondary ion emission.

2. $95 \%$ confidence interval includes the $t$-distribution factor for replicate cycles.

3. Corrected for instrumental mass fractionation (IMF) using the average of the IMF factors determined from the ANU 91500 (normalised to $\delta^{18} O_{S M O W}=9.86 \%$ ) and ANU AS3 (normalised to $\delta^{18} O_{S M O W}=5.34 \%$ ) datasets. 